International Journal of Engineering \& Technology, $7(3.2)(2018) 703-708$
International Journal of Engineering \& Technology
SPC
Website: www.sciencepubco.com/index.php/IJET
Research paper

\title{
Cross-Point Comparison of Multistage Non-Blocking Technologies
}

\author{
Muhammad Zulfin ${ }^{1 *}$, S Suherman', Rahmad Fauzi ${ }^{1}$, M. Razali², Maksum Pinem1 \\ ${ }^{1}$ Electrical Engineering Department, Universitas Sumatera Utara, Medan, Indonesia \\ ${ }^{2}$ Electrical Engineering Department, Institut Teknologi Medan, Medan, Indonesia \\ *Corresponding author E-mail: m.zulfin@usu.ac.id
}

\begin{abstract}
Multistage switching networks play important role in communication and computer network. They make communication nodes connect to each other. In computer hardware switches connect processors and memories. Initially, switches are arranged as one stage interconnection. As clients are growing, multistage is a must. The finding Clos multistage switching initiated multistage technologies. Benes improves Clos by reducing number of cross-points by using a 2 x 2 switch element and call re-routing. Batcher improves the technology by other way which is sorting destination address. Banyan is then joined to Batcher to simplify routing control. This paper analyses the number of cross-point required in Clos, Benes and Batcher Banyan to accomplish multistage switching architecture of 16, 64, 256, 1024 and 2048 input/output ports. As results, Clos cross-point is in averages 495.24\% higher than Benes and 160.30\% higher than Batcher Banyan. Clos blocking probabilities are closed to zero. Benes blocking probabilities are conditionally zero. Batcher Banyan blocking probabilities are zero.
\end{abstract}

Keywords: Multistage switching, Clos, Benes, Batcher Banyan, Cross-points

\section{Introduction}

Demand on switching technologies follows the growth of communication users. Switches route calls (on circuit switching network) and packets (on packet switching network) from sources to destinations[1]-[3]. A Switching speed is urgently required as transmission speed advances. Therefore, nonblocking switching is a necessity. The story of multistage switching started when Charles Clos published his finding of multistage interconnection network in 1953 [4]. Rather than using an $\mathrm{N} \times \mathrm{N}$ switching network that results $\mathrm{N}^{2}$ switching elements, Clos 3 stages switching produces smaller number of switching elements. Switch reduction constitutes to blocking probability. However, at Clos architecture, if the switch module at middle stage follows $m>=2 n-1$, switch is non-blocking [4]. Ten years after this finding, Benes published his research on Clos cross-point reduction without suffering network blocking. This is achieved by replacing switching elements at any stage by using $2 \times 2$ switching elements and dividing middle switches to N/2 x N/2 elements (Benes, 1962). However, Benes multistage switching is non-blocking re-configurable where new calls are set up by using idle input-output terminals and re-routing the existing calls. This re-routing process requires routing algorithms which were proposed by many researchers. Looping procedure was proposed by [5], parallel routing was proposed by [6], matrix based algorithm was proposed by [7], and division routing algorithm and input/output algorithm proposed in [8]. The drawback is, Benes network needs a complex control to accommodate new calls [9].

There are more researchers working on switching architecture, including adopting optical switching. Speeds of transmission lines have reached terabits per second. Many of this high speed links go to single switching point, so the switching speed and non-blocking states should be able to accommodate it. As an initial work, this paper discusses the basic architecture that forms switching design including Clos, Benes and Batcher Banyan and compares the cross-point number to realize the $\mathrm{N} \times \mathrm{N}$ switching matrix.

\section{Interconnecting Network}

Terminals in computer and communication devices communicate through interconnection[10], [11]. The bus topology is no longer effective as it is not scalable, adjustable and assessable. It is also intolerant to errors. Therefore, switching topology offers promising connection as it is able to connect terminal directly. Figure 1 shows a full squared crossbar switch that is able to connect all inputs to all outputs. The $\mathrm{N}^{2}$ cross-points are expensive so that point reduction is necessary. Multistage switches give better choice [12]. 


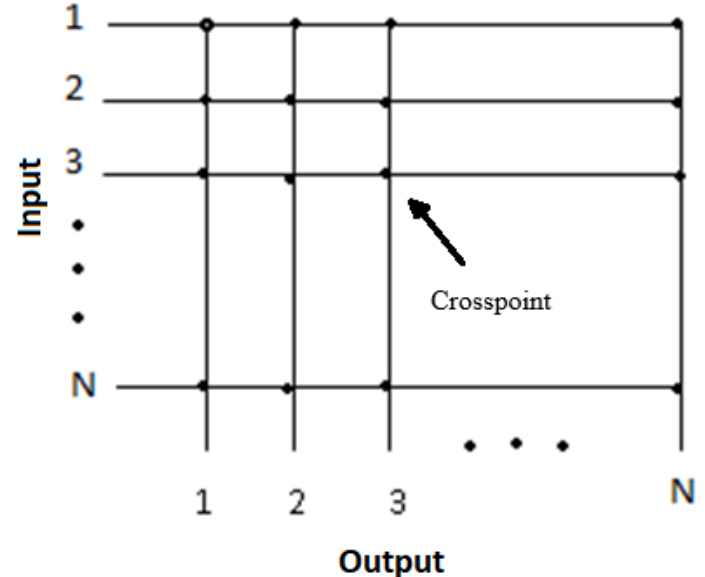

Fig.1: Crossbar Architecture

\section{Multistage Interconnecting Networks}

Multistage interconnecting networks are proposed by researchers including Banyan [13], Delta, Cube, Omega, Clos [4], Benes [14], Batcher [15], and Batcher Banyan [16]. Multistage switching is interesting as it offers the unblocking characteristics and fewer cross-points. The non-blocking multistage interconnecting networks are categorized into three categories[14]:

a. Non-blocking in strict sense: the non-blocking state stays whatever the input-output states. The inputs-outputs are always connectable and not depending to other calls.

b. Non-blocking in wide sense: it follows a particular rule that a condition should be fulfilled by a new call so that the route is non-blocking.

c. Rearrangeably non-blocking: some multistage interconnecting networks are reconfigurable, others are not. In order a new call is non-blocking; the existing call should be rearranged.

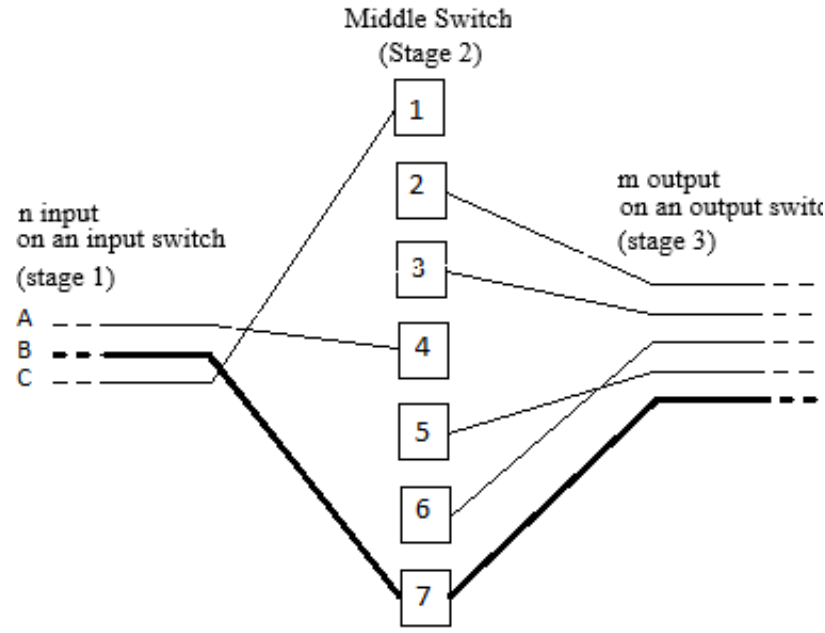

Fig.2: Second stage switch element calculation

\subsection{Closs Three Stage Switching}

At the Clos three stage switching, number of switch elements at the second stage determines the switch blocking probability. In order to find the suitable non-blocking probability number of elements, Figure 2 is employed. If there are $n$ inputs of the first stage switch and $\mathrm{m}$ outputs of the third stage, then the connection from input $\mathrm{B}$ to output $\mathrm{H}$ requires sufficient switches so that other (n-1) inputs and other (m-1) outputs can be connected through neighboring switches. The required switches are $(n-1)+$ $(m-1)+1$ or $n+m-1$. If $n=m$, then number of switches is $2 n-$ 1. For large input/output $N$ then the cross-point $(\mathrm{CP})$ is $6 \mathrm{~N}^{3 / 2}$
3N [4]. The Clos three stage switching is shown in Figure 3.

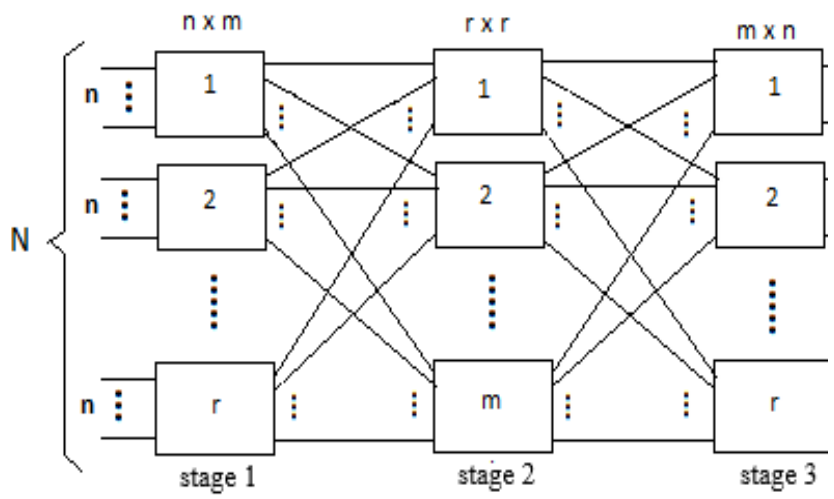

Fig.3: Clos three stage switching

The first stage contains $\mathrm{r}$ switching elements of $\mathrm{n} \times \mathrm{m}$ switches with input $\mathrm{n}=\mathrm{N}^{1 / 2}$. The second stage contains $\mathrm{m}$ switching elements of $r \times r$ with $r=N / n$. The third stage contains $r$ switching elements of $\mathrm{m} \times \mathrm{n}$. In order to make non-blocking switch, the $\mathrm{m}$ $\geq 2 \mathrm{n}-1$ should be fulfilled. For instance, the three stages Clos with $\mathrm{N}=16, \mathrm{n}=161 / 2=4$. So $\mathrm{m}$ should be $\mathrm{m}=2.4-1=7$. If $\mathrm{n}$ $=\mathrm{m}=4$ the switch is non-blocking but rearrangeably nonblocking which requires routing algorithms. In order to obtain the probability of Clos three stage non-blocking network Graph theory [17] is employed. Figure 4 assists the probability derivation.

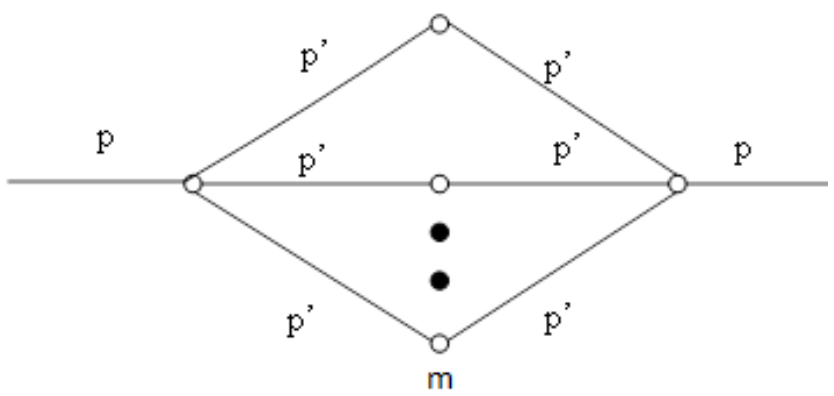

Fig.4: Graph of three stage switching

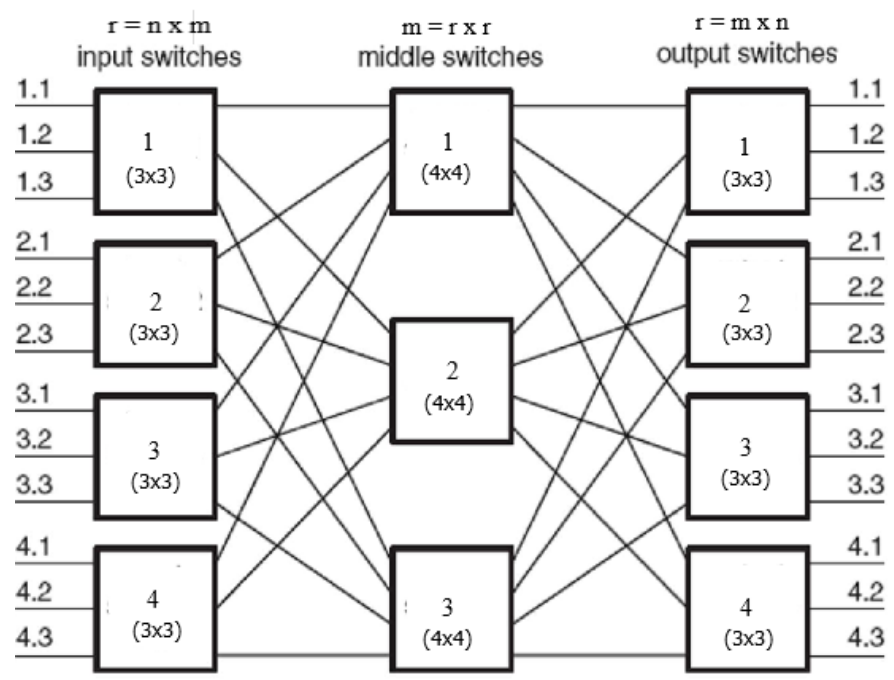

Fig.5: Clos switching network $(3,3,4)$ 


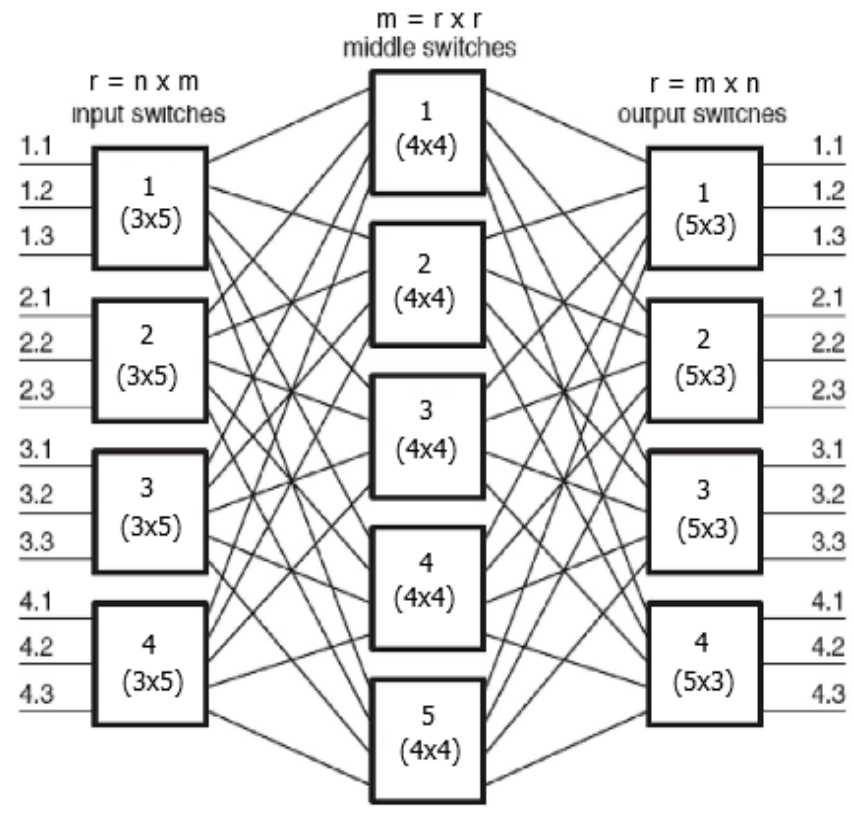

Fig.6: Clos switching network $(5,3,4)$

If $\mathrm{p}$ is the probability an input to an output link busy, then probability of a link between first and second stages is busy expressed as function belo

$\mathrm{p}^{\prime}=\mathrm{p} / \mathrm{m}$

Since there are $\mathrm{m}$ possible routes in network, then the blocking probability $\mathrm{P}_{\mathrm{b}}$ be:

$\mathrm{P}_{\mathrm{b}}=\left[1-\left(1-\mathrm{p}^{\prime}\right)^{2}\right]^{\mathrm{m}}$

Since the first and the third stages are symmetric, then the characteristic is represented by triple $(\mathrm{m}, \mathrm{n}, \mathrm{r})$ where $\mathrm{m}$ is middle switch, $n$ is input or output ports of first or third stage, $r$ is number of input and output switches. For instant, Clos network $(3,3,4)$ refers to $m=3, n=3, r=4$. Stage 1 has 4 switching elements of $3 \times 3$, stage 2 has 3 switching elements of $4 \times 4$ and third stage has 4 switching elements of $3 \times 3$. Figure 5 shows the Clos $(3,3,4)$ and Figure 6 shows Clos $(5,3,4)[18]$.

On the other hand, Clos $(3,3,4)$ in Figure 5 is rearrangeably nonblocking as $m=3<2 n-1=5$. This mean input port is always connectable to output port given that existing call re-routed through middle stage switches.

\subsection{Benes Multistage Switching}

Benes network is rearrangebly non-blocking Clos three stage switching with $M S=2$ and $a=b=2$, where MS is middle switch, a is number of inlet of each switching element and $b$ is the output. Clos architecture can be modified to be Benes by adjusting $\mathrm{m}=$ $\mathrm{n}=2, \mathrm{r}=\mathrm{N} / 2$ and $\mathrm{N}>4$ where $\mathrm{N}$ is input or output number, written as Clos $(2,2, \mathrm{~N} / 2)$. Figure 7 shows $\mathrm{Clos}(2,2, \mathrm{~N} / 2)$ with $\mathrm{N}$ inputs, every switch has inlet $\mathrm{n}=2$, outlet $\mathrm{m}=2$ and middle stage (MS) $\mathrm{M}=2$ and input switch $\mathrm{r}=\mathrm{N} / 2$ [14].

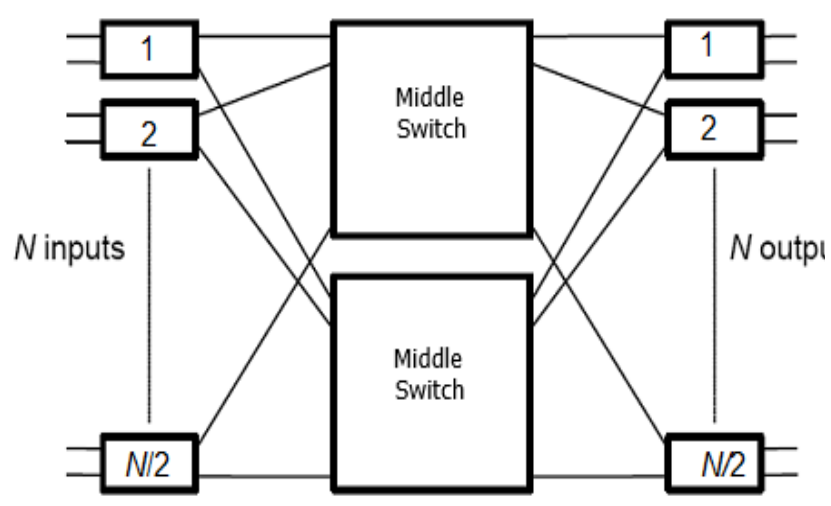

Fig.7: Clos $(2,2, N / 2)$

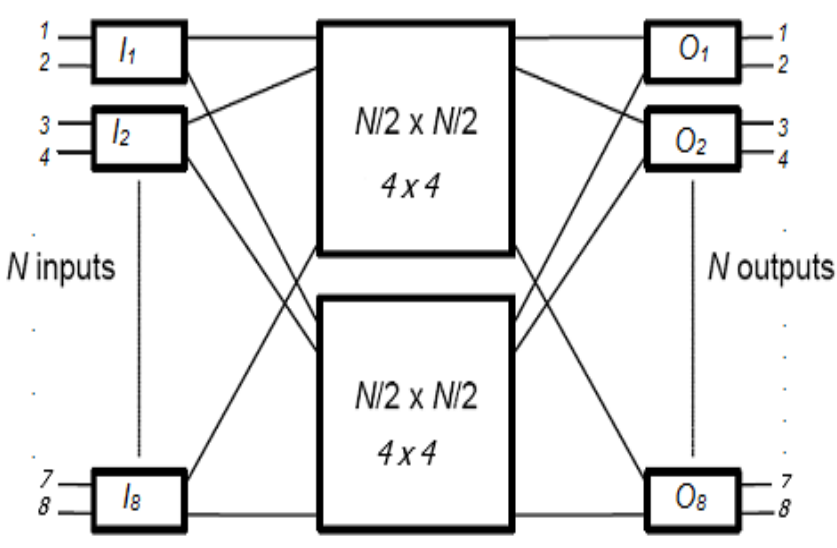

Fig.8: Clos middle switch 4 x 4

The middle stage switch is then $\mathrm{N} / 2 \times \mathrm{N} / 2$ as shown in Figure 8 . By replacing middle switch to be of $2 \times 2$ elements, the Benes network is achieved. Figure 9 shows the complete Benes network.

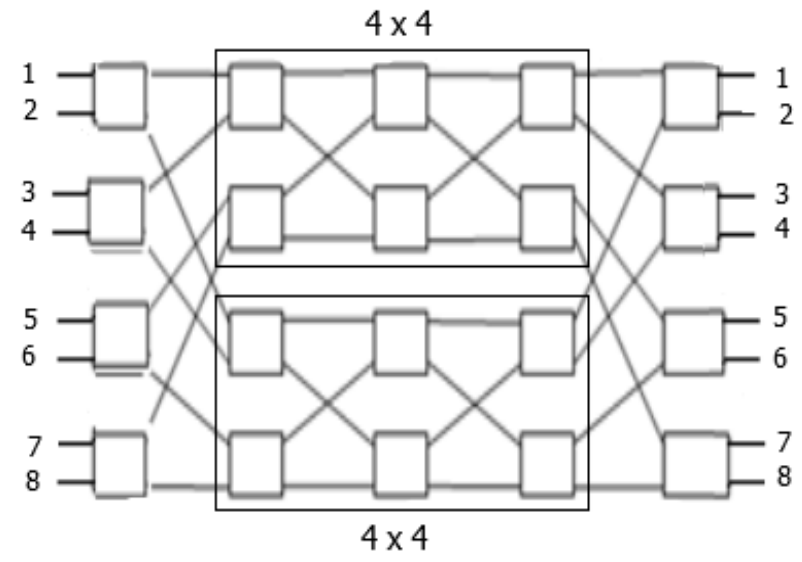

Fig.9: Benes multistage switching $8 \times 8$

To develop Benes multistage switching 16 x 16 (Figure 10), Benes $8 \times 8$ is to be the middle switch and so on. If Benes $\mathrm{N} \times \mathrm{N}$ is built then N/2 $x \mathrm{~N} / 2$ is the middle switch. 


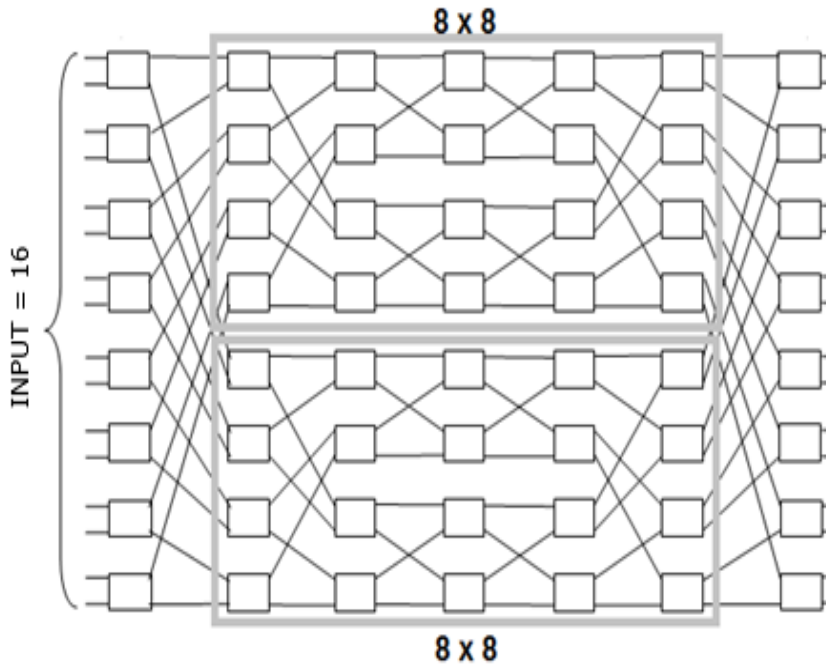

Fig. 10: Benes multistage switching $16 \times 16$ with middle switch $8 \times 8$

If Benes has $\mathrm{N}$ input-output, then number switch stage (S) is $\mathrm{S}=$ $2 \log _{2} \mathrm{~N}-1$ with each stage has $\mathrm{N} / 2$ switch elements of $2 \times 2$. Total switching element is $\mathrm{SE}=\mathrm{N} \log _{2} \mathrm{~N}-\mathrm{N} / 2$ and total cross-point is $\mathrm{CP}=4\left\{\mathrm{~N}_{\log } \mathrm{N}-\mathrm{N} / 2\right\}$. For instance, Benes switching $16 \times 16$ has $2 \log _{2} 16-1=7$ stages, $16 \log _{2} 16-16 / 2=72$ switching elements and $4\left\{16 \log _{2} 16-16 / 2\right\}=224$ cross-points.

The following Figure 11 is an example of route change in each switching element to connect input - output pairs of 0-3, 1-0, 2-7, $3-1,4-4,5-6,6-2,7-5$ by using division routing algorithm [8].

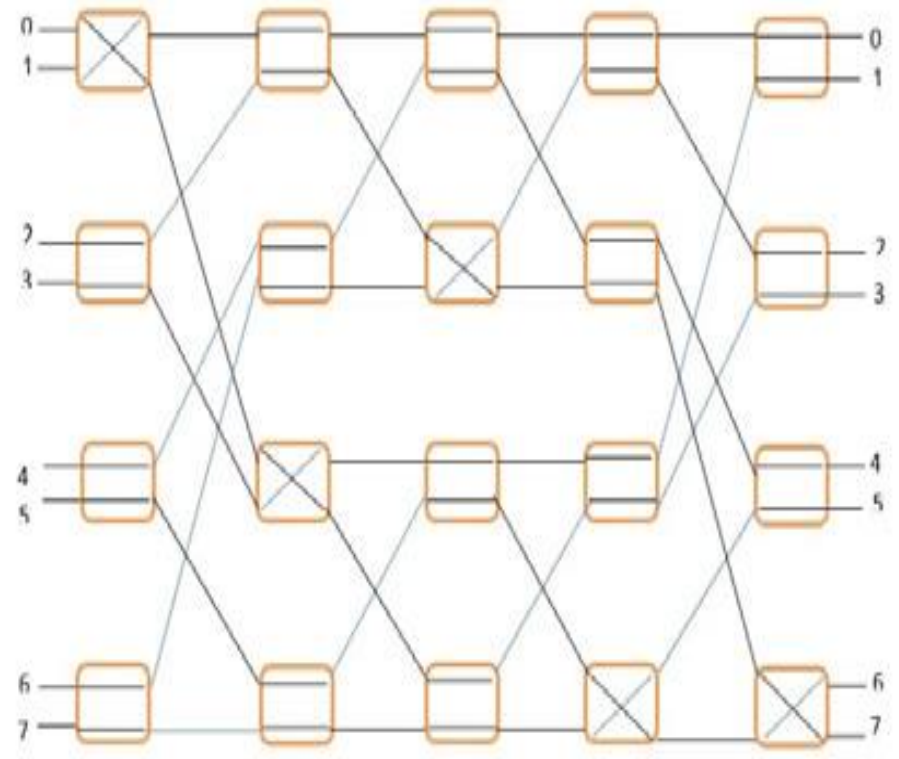

Fig.11: Benes 8 x 8 for pairs: 0-3, 1-0, 2-7,3-1, 4-4, 5-6, 6-2, 7-5.

By using the same input-output pairs the route arrangement can be refigures as in Figure 12. The algorithm employed is input and output algorithm. It proofs that rearrangeable non-blocking of Benes network in transferring pairs of $0-3,1-0,2-7,3-1,4-4$, 5-6, 6-2, 7-5 can be performed through inter-stage links without conflict so that blocking probability is zero.

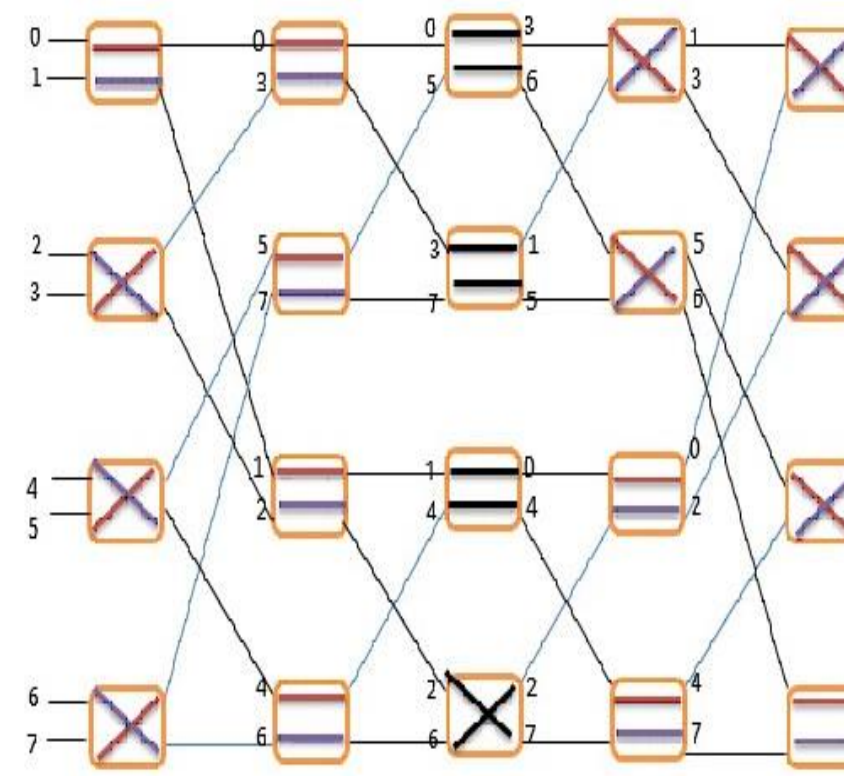

Fig.12: Rearranged route for pairs 0-3, 1-0, 2-7, 3-1, 4-4, 5-6, 6-2, 7-5.

\subsection{Batcher Banyan Multistage Switching}

Batcher Banyan multistage switching is a combination of two switching networks that have different topologies forming a multistage network. Banyan is a self-routing where packets routed based on destination address on packet headers. Selfrouting reduces control complexity. Banyan with $\mathrm{N}$ input/output has $\log _{2} \mathrm{~N}$ switching stages and $\mathrm{N} / 2 \log _{2} \mathrm{~N}$ switching elements. The total cross-point number is $2 \mathrm{~N} \log _{2} \mathrm{~N}$ for switching size $\mathrm{N} \mathrm{x}$ $\mathrm{N}$ [13].

However, Banyan is a blocking switch. Conflict occurs when two packets has the same outlet at a switching element. Figure 13 shows how blocking occurred at Banyan $8 \times 8$ for inputoutput pairs 000-011, 001-111, 010-001, 011-110, 100-010, 101-100, 110-101 and 111-000 [19].

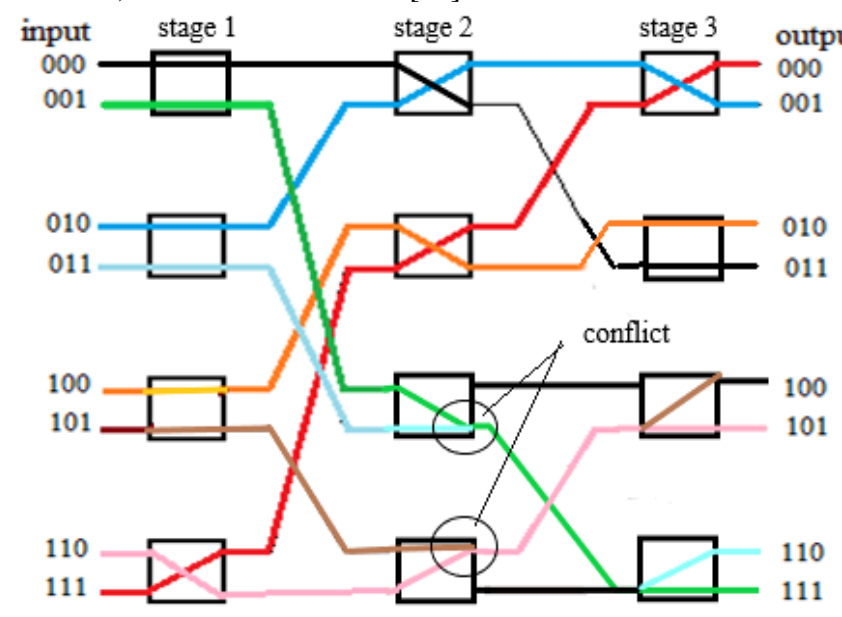

Fig.13: Blocking at Banyan switch

As shown in Figure 13, two conflict packets occurred at the second stage, where two packets contended the same link output. This cannot be solved by Banyan itself. One of the solutions is by placing a Batcher network back-to-back. Batcher performs sorting before packets enter Banyan. However, before entering Banyan, packets should be shuffled deciding the new input port for Banyan. Figure 14 shows the link shuffle [20]. 


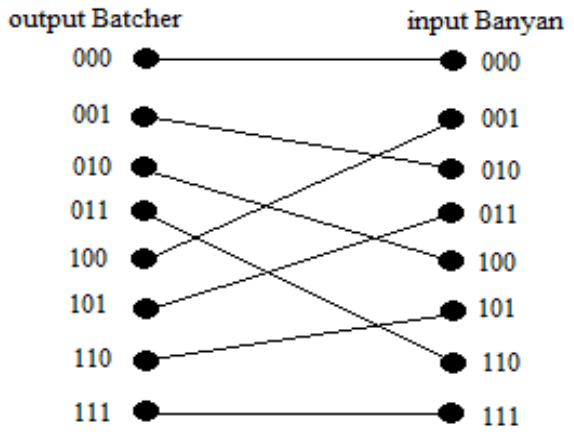

Fig.14: Link Shuffle

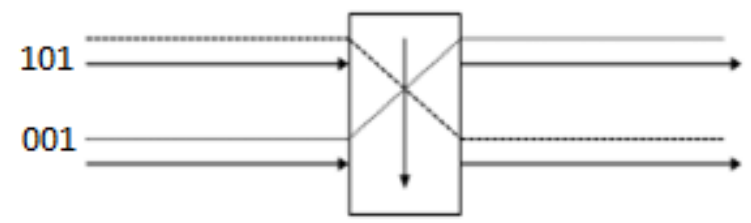

(a)

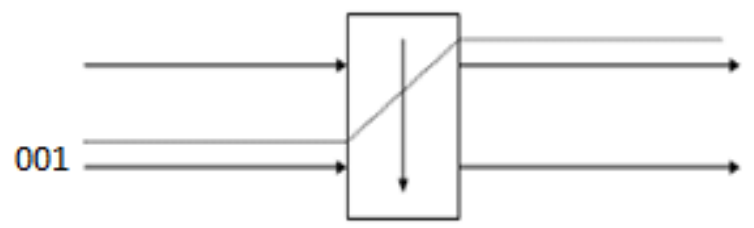

(b)

Fig.15: Batcher switch

Batcher switch is built by $2 \times 2$ switch elements that work as a sorter, the address bits with higher value goes to output port pointed by the arrow (Figure 15a) [15]. But if there is only one input packet, the chosen output is at the beginning of arrow (Figure 15b).

Batcher network of $\mathrm{N}$ inputs has $\mathrm{N} / 2$ switch per stage, $\log _{2} \mathrm{~N}\left(1+\log _{2} \mathrm{~N}\right) / 2$ number of stages and $\mathrm{N} \log _{2} \mathrm{~N}$ switching element. Batcher with 8 inputs has 6 stages, 4 switches per stage and total 24 switching elements as shown in Figure 16.

Batcher Banyan size $\mathrm{N}$ has $\mathrm{N} / 2$ switch per stage, $\log _{2} \mathrm{~N}\left(1+\log _{2} \mathrm{~N}\right) / 2$ stages and $\mathrm{N} \log _{2} \mathrm{~N}$ switching elements. Figure 17 shows Batcher Banyan switching 8 x 8 [21].

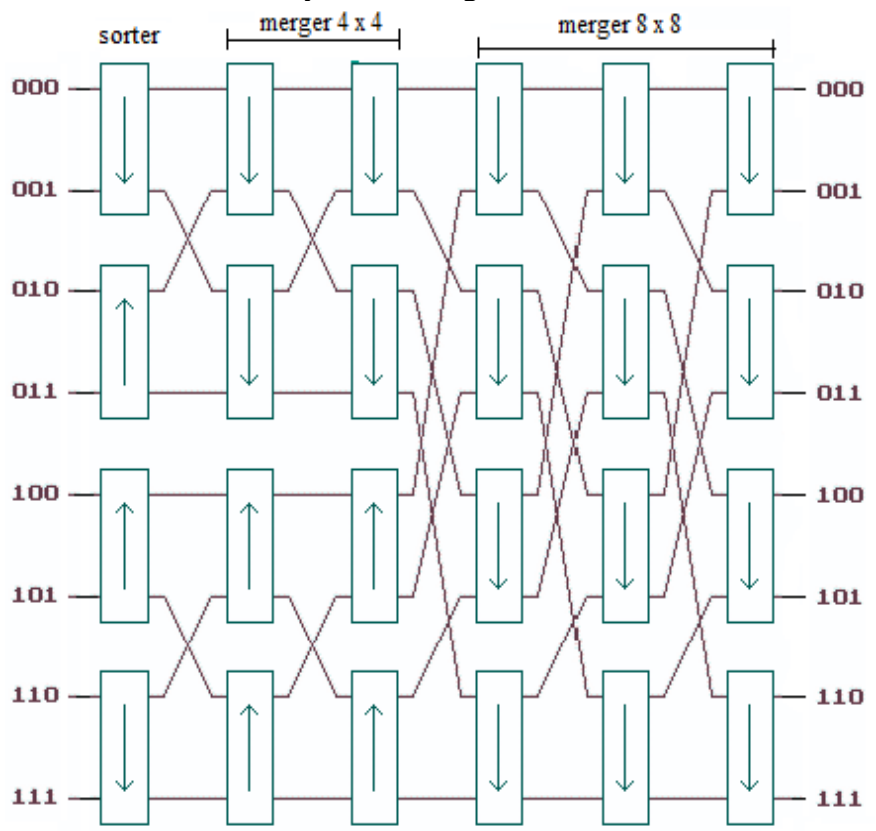

Fig.16: Batcher $8 \times 8$

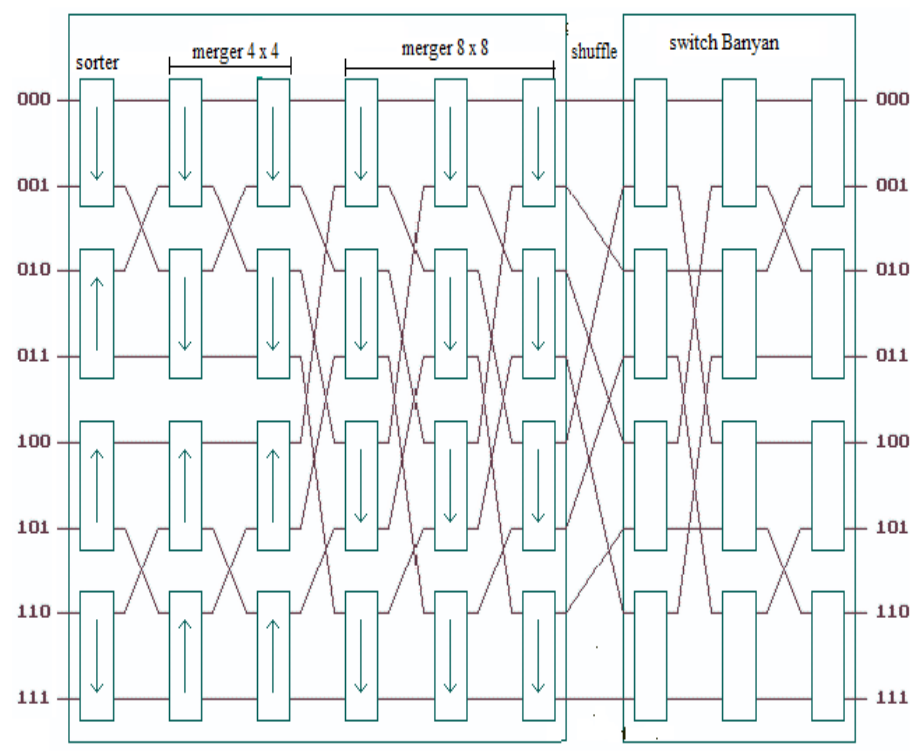

Fig.17: Batcher Banyan 8 x 8 .

Batcher Banyan works as follows (Figure 18). Batcher sorts input packets according the address bits as pointed by the arrows There are two mergers: $4 \times 4$ and $8 \times 8$. The merger switches forwards packet as the sorter to the intended output port. After passing Batcher, packets get through shuffle links. Shuffle links forward packets to the correct Banyan inputs ports. Banyan directs packets to the intended output. Figure 18 shows routing in Batcher Banyan for pairs: 000-111, 001-010, 010-100, 011101, 100-000, 101-110, 110-011 and 111-001. No conflict occurs in routing.

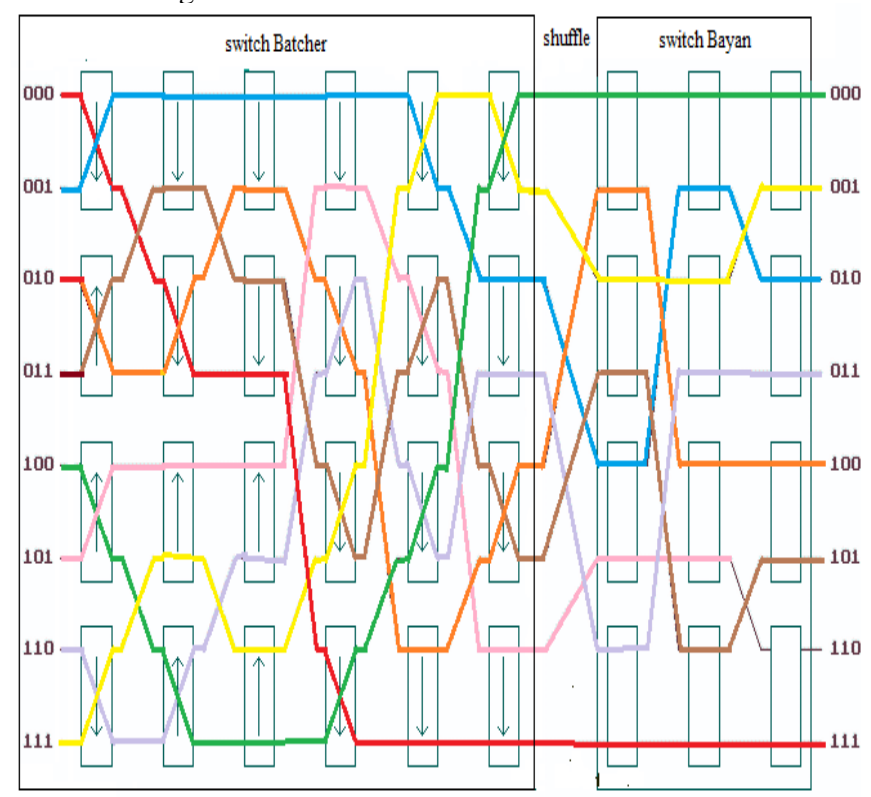

Fig.18: Routing in Batcher Banyan

\subsection{Multistage Switching Cross-Point Comparison}

As the results of analysis in previous section, the numbers of cross-points required to develop multistage switching of Clos, Benes and Batcher Banyan for size $\mathrm{N} x \mathrm{~N}$ with $\mathrm{N}$ is 16, 64, 256, 1024 and 4096 are shown in Table 1 . Benes has the smallest number of cross-point, followed by Batcher Banyan and Clos.

Table.1: Cross-point Comparison

\begin{tabular}{|c|c|c|c|}
\hline \multirow{2}{*}{ Input-Output Number (N) } & \multicolumn{3}{|c|}{ Cross-points } \\
\cline { 2 - 4 } & Clos 3 Level & Benes & Batcher Banyan \\
\hline 16 & 336 & 224 & 256 \\
\hline 64 & 2.880 & 1408 & 2176 \\
\hline
\end{tabular}




\begin{tabular}{|c|c|c|c|}
\hline 256 & 23808 & 7680 & 12288 \\
\hline 1024 & 193536 & 38912 & 61440 \\
\hline 4096 & 1560576 & 86016 & 294912 \\
\hline
\end{tabular}

Table 2 shows the blocking probabilities. The probability of blocking of Clos multistage switching closes to zero. When $\mathrm{m}>=2 \mathrm{n}-1$, Clos network is strictly non-blocking. Likewise, Benes probability of blocking is zero given that re-routing is performed. Batcher Banyan on the other hand give zero probabilities without condition as sorting avoid collision.

Table.2: Blocking Probabilities Comparison

\begin{tabular}{|c|c|c|c|}
\hline \multirow{2}{*}{ Input-Output Number (N) } & \multicolumn{3}{|c|}{ Blocking Probability } \\
\cline { 2 - 4 } & Clos 3 level & Benes & Batcher Banyan \\
\hline 16 & $6.3 \times 10^{-2}$ & 0 & 0 \\
\hline 64 & $6.6 \times 10^{-3}$ & 0 & 0 \\
\hline 256 & $6.8 \times 10^{-5}$ & 0 & 0 \\
\hline 1.024 & $6.8 \times 10^{-9}$ & 0 & 0 \\
\hline 4.096 & $6.9 \times 10^{-17}$ & 0 & 0 \\
\hline
\end{tabular}

\section{Conclusion}

The paper has analyzed three types of multistage switching: Clos, Benes and Batcher Banyan. Clos has the highest number of cross-points, followed by Benes and Batcher Banyan. In average Clos cross-point is $495.24 \%$ higher than Benes and $160.30 \%$ higher than Batcher Banyan.

Clos blocking probabilities are closed to zero. Benes blocking probabilities are zero given that complex control algorithm successfully rearrange connection. Finally Batcher Banyan produces zero probabilities easily as sorting is applied.

\section{Acknowledgement}

This research was funded by Research Institute of Universitas Sumatera Utara under TALENTA grant for Research Contract of Fiscal Year 2018.

\section{References}

[1] Sani A, "Multistage switching hardware and software implementations for student experiment purpose," IOP Conf. Ser. Mater. Sci. Eng., vol. 309, no. 1, p. 012097, 2018.

[2] A. Putera, U. Siahaan, and R. Rahim, "Dynamic Key Matrix of Hill Cipher Using Genetic Algorithm," Int. J. Secur. Its Appl., vol. 10, no. 8, pp. 173-180, Aug. 2016.

[3] R. Rahim, "Man-in-the-middle-attack prevention using interlock protocol method," ARPN J. Eng. Appl. Sci., vol. 12, no. 22, pp. 6483-6487, 2017.

[4] C. Clos, "A Study of Non-Blocking Switching Networks," Bell Syst. Tech. Journal., 1953.

[5] Opferman D.C. and Tsao-Wu, "On a Class of Rearrangeable Switching Networks,” Bell Syst. Tech. Journal, vol. 50, no. 5, 1981.

[6] L. E. and Z. S.Q., "Parallel routing algorithms for non blocking electronic and photonic switching networks," IEEE Trans. Parallel Distrib. Syst., vol. 16, no. 8.

[7] S. Chakrabarty, A., Collier, M., Mukhopadhyay, "Matrix-Based Nonblocking Routing Algorithm for Benes Networks," Comput. World Futur. Comput. Serv. Comput. Cogn. Adapt. Content, Patterns.

[8] A. Karimi, "Introduction And Analysis Of Optimal Routing Algorithm In Benes Networks," Int. Conf. Robot PRIDE 2013 2014 - Med. Rehabil. Robot. Instrum.

[9] L. G. V. G. F. Lev, N. Pippenger, "A Fast Parallel Algorithm for Routing in Permutation Networks," IEEE Trans. Comput., vol. 30, no. 2, pp. 93-100, 2015.

[10] T. Listyorini and R. Rahim, "A prototype fire detection implemented using the Internet of Things and fuzzy logic," World Trans. Eng. Technol. Educ., vol. 16, no. 1, pp. 42-46, 2018.

[11] D. Subramaniam et al., "A Stacked Planar Antenna with Switchable Small Grid Pixel Structure for Directive High Beam Steering Broadside Radiation," Int. J. Eng. Technol., vol. 7, no.
2.5, pp. 122-127, Mar. 2018.

[12] I. R. Quadri, "Modeling of Topologies of Interconnection Networks based on Multidimensional Multiplicity.," Rap. Rech. Inst. Natl. Rech. En Inform. En Autom., pp. 5-16, 2007.

[13] G. J. Goke L.R. dan Lipovski, "Banyan Networks for Partitioning Multiprocessing Systems," in Proceeding 1st Annual Computer Architecture Conference, 1973, pp. 21-28.

[14] V. E. Benes, "On Rearrangeable Three-Stage Connecting Networks.," Bell Syst. Tech. Journal., 1962.

[15] K. E. Batcher, "Sorting Networks and Their Applications," Spring Jt. Comput. Conf. Goodyear Aerosp. Corp. Akron, Ohio, vol. 32, pp. 307-314, 1968.

[16] M. J. Narashima, "The Batcher-Banyan Self-Routing Network: Universality and Simplification," IEEE Trans. Commun., vol. 36, no. 10,1988 .

[17] C. Y. Lee, "Analysis of Switching Networks," Bell Syst. Tech. Journal., 1955.

[18] B. Dally, William J. and Towles, Principles and Practices of Interconnection Networks. Morgan Kaufmann Publishers: San Francisco.

[19] M. Zulfin, "Perbaikan Internal Blocking Jaringan Switching Banyan dengan Penyortir Batcher," J. Ilm. Teknol. Harapan, vol. 5 , no. 2, 2015

[20] J. H. Patel, "Performance of Processor-Memory Interconnections for Multiprocessors," IEEE Trans. Comput., vol. 30, no. 10, 1981.

[21] D. K. Hunter, "Encyclopedia of Information Technology," Encyclopedia of Information Technology. Marcel Dekker, New York., p. Vol. 42 No.27, 1997. 